\title{
Exploring the role of E-maintenance for value creation in service provision
}

\author{
Maria Holgado, Marco Macchi \\ Dept. of Management, Economics \& Industrial Engineering \\ Politecnico di Milano \\ Milan, Italy \\ maria.holgado@polimi.it; marco.macchi@polimi.it
}

\begin{abstract}
Technological innovations has always played an important role in economic growth and industrial productivity, but they have also potential to influence service industry. In particular, they can offer support to the process of servitization in manufacturing companies. This article presents a study regarding the prospective value that different technological innovations can offer to maintenance service provision. A review of different baseline technologies and a categorization of several types of E-maintenance tools and applications has been carried out in order to understand the new functionalities that can potentially bring to the provision of smart maintenance services. Moreover, a value analysis method for representing the contribution of tool categories to several value dimensions is presented here. This method can be used for identifying the best technological solution, matching both customer value and provider value, i.e. conforming a win-win situation for the parties involved in the service provision. Some preliminary results based on a survey are eventually given as a first test of its applicability.
\end{abstract}

Keywords - E-maintenance, maintenance technology, value creation, servitization, maintenance services, smart services

\section{INTRODUCTION}

Technological advances and the diffusion of technological knowledge have led the spread of the economic growth worldwide [1] and are related to concrete industrial structures [2] as well as to industrial development and productivity growth [3]. Technological innovations, i.e. those innovations that embody inventions from the industrial arts, engineering, applied sciences and/or pure sciences [4], have driven the evolution of manufacturing paradigms [5]. Innovations based on information-based, web-enabled and predictive technologies are driving transformations in manufacturing industry, bringing up concepts such as e-manufacturing [6] and smart manufacturing [7].

E-maintenance as a concept is often discussed in literature as linked to both the emergence of new e-technologies for maintenance optimization and to a new way of thinking maintenance as a supporting pillar of e-manufacturing and ebusiness [6][8][9][10]. Moreover, E-maintenance is seen as a means for supporting customers anywhere and anytime [6][11]; thus, it is then envisaged to have the potential of supporting Original Equipment Manufacturers (OEMs) in the provision of maintenance services. OEMs are eager to increase their offering of industrial services to current or potential new customers by introducing technological innovations [12] as a strategy to achieve a differentiation in their integrated product and service offerings [13]. Industrial services are related to the provision of after-sales services and customer support regarding both spare parts and maintenance of industrial equipment [14]. The shift towards a service-oriented approach have affected the perception of value. Value from a service perspective is not anymore based on the exchange-value defined by manufacturers but on the value-in-use determined by the customer according to the perceived benefits of the service [15] and the provider perspective of value-in-offering [16]. Ojanen et al. [17] state that more research needs to be done regarding the identification of the value elements in maintenance service provision and the definition of measurement procedures to assess value from customers and providers viewpoints.

This paper explores the role that technological innovations in industrial maintenance can bring to the provision of maintenance services; thus, a specific type of service is addressed here: technology-based maintenance services, in the remainder named as smart maintenance services. Concretely, the main objectives of the paper are: (i) to study the new functionalities that innovative tools and applications can bring to the provision of smart maintenance services; (ii) and to analyze their contribution to a concrete set of value dimensions in order to investigate how different defined tool categories or a combination of them could influence the value created by smart maintenance services.

\section{BACKGROUND}

This section introduces a review of servitization and Emaintenance concepts and an analysis of main dimensions for value creation through smart maintenance services provision. 


\section{A. Servitization in manufacturing and E-maintenance}

Servitization is widely recognized as "the process of creating value by adding services to products" [13]. It has been identified as an emerging trend among equipment manufacturers [18][19][20] and it frequently occurs due to three types of drivers [13][18]: financial (e.g. revenue stream and profit margin); strategic (e.g. competitive opportunities and advantage); and marketing drivers (e.g. customer relationships and product differentiation). OEMs following a servitization strategy begin the process by offering few product-related services and then adding more services targeting the end-user's processes, as they get consolidated in the service market [18]. This shift also implies the adoption of a more customer centric approach, by offering customized solutions instead of just products [13] and, in some cases, even incorporating products from other manufacturers to the solution offering [21][22].

The importance of E-maintenance technologies for customer support services has been hinted by several authors [6][11][23]; due to their potential to provide real-time data regarding operation and maintenance conditions and real-time support to decision making. E-technologies are a means for communication, processing and storage of information to offer the technical support to access remote information and support maintenance decision making [11]. In this regard, remote monitoring technology is seen as an enabler of servitization in manufacturing by providing real-time data about the status, operational performance and location of manufacturer's products in the field [24].

\section{B. Value creation in smart maintenance services}

The emphasis of the service is in "the process of doing something for and with another entity in order to create value" [25]. Thus, this involves implicitly and actively the customer in the process of value creation [15] and brings new perspectives and benefits into the service development process. For example, Carbonell et al. [26] confirm that customer participation during the service development process improves the technical quality and the time-to-market of the new service offerings. The value is then created by and for all entities involved in the provision of the service, i.e. service provider, customer and third parties.

Ali-Marttila et al.[27] have investigated the most valued elements in the provision of maintenance services for both customers and service providers. Their results show that customers rank differently the importance of the value elements depending on whether the target item of the service is highly critical for the operations or not, while not significant difference was found among the value elements ranked by service providers between core and support services. Fig. 1 shows the top five valued elements that customers identified for high critical and low critical items.

Fig. 1. Value elements for customers of a maintenance service, from [27]
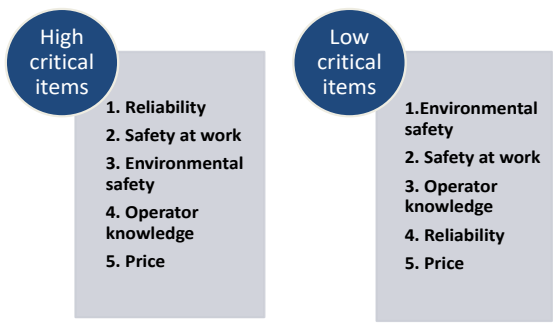

Toosi et al. [28] studied different dimensions regarding perception of value by customers of maintenance services. Their results suggest sectorial differences, although some dimensions obtained a high position in all companies, such as accessibility of service provider. The six most important value dimensions, analyzed according to frequency and variability of their presence in the interviews, are the following (in order from higher to lower positions): specialist knowledge, accessibility of service provider, relational dynamic, range of products and services, delivery and pricing. It is interesting to note that, similarly as the previous study by [27], the price of service is between the most valued elements but not occupying the highest positions in the rankings. Indeed, [28] mention that it seems that customers do not value the maintenance service according to the cost savings that can potentially be obtained but by the price they pay for the service.

According to [17] the assessment of value elements have to be done by considering: (i) the composition and features of the services and; (ii) the capabilities and know-how of the service providers. Nevertheless, the previous studies do not focus on the composition or specific features of maintenance services, neither on the specific case of smart services which could bring new functionalities and new ways for value creation.

Smart services are fundamentally preemptive, i.e., actions to be taken are based upon actual evidence from field intelligence [29], which can be embedded within the equipment or provided by smart devices or sensors and it is based on real time field data. Additional value created by smart maintenance services would potentially lead to extend the equipment life, reduce the downtime, increase product quality, decrease cost and increase overall productivity [30]. Moreover, as [29] claim it will provide another type of value; "the value of removing unpleasant surprises" by anticipating equipment behaviour and potential failures. On the other hand, the service provider would have the opportunity of creating long-lasting relationships with the customer [31] and of learning from their interaction more about customers' concrete needs and specific operation conditions [24]. This knowledge would provide the proper feedback to improve the service offering to better match actual customer needs and requirements [12][24][29].

\section{TECHNOLOGICAL COMPOSITION OF SMART MAINTENANCE SERVICES}

As mentioned above, smart maintenance services are built on field intelligence that is provided by technology either embedded in a product/equipment or facilitated by the use of devices, sensors or any other technology-based tools. Smart maintenance services can create better value through the application of different technologies which are of different 
nature and can be seen at different constituting levels. Fig. 2 shows the illustration of the two technological levels in the constitution of smart maintenance services: the level of baseline infrastructure and the level of innovative tools \& applications. Different choices at both levels would conform different configurations and therefore, provide different features and functionalities to the smart maintenance services.

Fig. 2. Technological levels in the composition of smart maintenance services

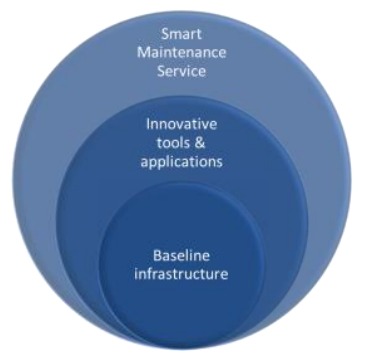

The technologies at the baseline infrastructure level are several kinds of technologies and computing approaches that could be used alone or combined in order to create the basic structure for the tools and applications at the next level. The different categories within this level are the following:

- Web technology, which uses multi-tier architecture for data and information sharing among the tiers, which "are like a platform where software programs and Web applications can be run on and be used for various tasks" [32]. Internet, intranet and Ethernet technologies are examples of web technologies.

- Wireless technology, whose main advantages compared to the wired systems are related to savings in networking cost and to its degree of flexibility [10]. It includes, among others, the following technologies: WLAN, WPAN, RFID, GPS, Bluetooth, ZigBee.

- Artificial Intelligence (AI), which is used to assist interpretation of fault data and degradation parameters, statistic failure analysis and prognosis and intelligent diagnosis [33]. Commonly used AI techniques are Expert Systems (ESs) and Artificial Neural Networks (ANNs), which are used alone or combined with others AI techniques to enhance diagnostics systems [34].

- Agent technology, which has evolved from distributed artificial intelligence [32]. There are different types of agents, such as intelligent agents, which can autonomously plan actions, interact with others and respond to dynamic and unpredictable situations [35], and mobile agents, which are able to move across the network [32].

- Computing methods, which encompasses different methods for processing information based on mathematical, numerical or logical methods. Examples of recent computing approaches are autonomic computing, grid computing and cloud computing. Autonomic computing brings to the system the capability of sensing its operating environment and taking decisions if needed to change the environment or its behavior [36]. Grid computing is a method of distributed computing which enables anyone in the grid to cooperate and access each other's information [37]. Several authors make a comparison between grid computing and cloud computing and see the latter as an evolution of grid computing, which provides a pool of information from which resources are retrieved ondemand [37][38]. Dillon et al. [39] see five fundamental elements of cloud computing: on-demand self-service, broad network access, resource pooling (to benefit from economies of scale and specialization), rapid elasticity in consumption and measured service level.

- Sensor technology, which allows to move from failures detection to degradation monitoring [40]. Additional capabilities provided by the advances of sensor technology, needed to convert sensors into smart sensors, are the following: two-way digital communication, self-identification, self-diagnosis and more powerful data processing [41]. There is a high variety of sensors; in the field of tool condition monitoring, a classification of sensors was given by [42], which consider in-process sensors as those monitoring during the machining operation, and incycle sensors as those operating through periodic examination. It is also possible to combine several sensors in network configurations [43] or use sensor fusion techniques to obtain mutual information from different sensors [44].

- Model-based technologies. Modelling technology in maintenance has been used for product life cycle management to carry out different evaluations in each product life cycle phase: for example, failure analysis in the planning phase or diagnosis in the operation phase [45]. Virtual product models may also be used for facilitating decision making in the design phase [46]. These technologies include product modelling, digital product modelling and 3-D modelling.

- Materials technology, which encompasses techniques based on materials science, such as thermography, ultrasonic, acoustic emissions and tribology, providing the characterization of physical properties of materials in order to monitor materials behaviors and detect defects and material deterioration [47]. As examples; changes in material density has been suggested as a potentially useful condition monitoring for insulation materials in nuclear power plants [48]; the emissions of infrared energy in machinery can determine their operating conditions [49]; and a spectral analysis could detect the loss of the protection capacity of a lubricant, so indicating that the lubricant needs to be changed [50]. Smart materials are those displaying some properties or responding to specific stimuli in a way that can be used as a monitoring parameter in a specific situation [51] and could be used to build up smart sensors or built-in test equipment [52]. 
The innovative tools \& applications encompasses the means that either alone or combined provide the new functionalities to the smart maintenance service offerings. They are founded on the baseline infrastructure elements, so being composed by a combination of the technologies mentioned above. It is worth mentioning that, even though not included as a category in the baseline infrastructure level, interoperability standards play an important role in the combination of different technologies and their use for configuring innovative tools \& application. Interoperability standards have been developed to ensure the integration and interoperation between technological components (see Chp. 5 in [53] for a review on interoperability standards in industrial and telecommunication sectors). The categories of innovative tools \& applications at this technological level are the following:

- Smart devices and sensors - Smart devices such as graphic tablets, PDA, smart tags are hardware devices which are equipped with wireless technologies in order to provide functionalities that support the operator in the field [10]. Smart sensors combine a sensing element with information processing and wireless technologies in order to improve their easiness of configuration and connectivity [41].

- e-CMMS - They are web-enabled computerized maintenance management systems (CMMS) which are able to monitor and manage preventive maintenance activities while connecting to mobile technologies for retrieving [10]. Duran [54] highlights the relevance of using a CMMS when the number of critical equipment is high or the need for maintenance resources management is significant.

- Inspection tools - Assets and equipment conditions could be measured through periodic inspection in order to detect failures and/or its degradation state. This inspections are performed manually or automatically. This category includes the tools used for those periodic inspections, such as NDT [55], a combination of vibration and lubrication analysis [50], power spectrum graph, phase spectrum graph [34], among others.

- Diagnosis tools - The heart of Condition-Based Maintenance (CBM) is condition monitoring, which encompasses: data acquisition, data processing and analysis, data interpretation and extraction of useful information from it [32]. Tools in this category are condition monitoring tools or fault diagnosis tools. Fault diagnosis can be done both manually, requiring specific expertise, or automatically, by the use of automatic pattern recognition which can classify signals based on the information and/or features extracted from the signals [34]. Diagnosis tools would perform automatic pattern recognition by using different approaches, connected to different baseline technologies explained above as AI or model-based technologies.

- Prognosis tools - Prognosis and Health Management (PHM) is a natural extension of the CBM approach that aims at predicting, with some level of confidence and by identifying trends in degradation parameters, when the equipment is going to fail [5]. Concretely, prognostics "attempts to predict faults or failures before they occur" [34]. Although sharing the same principles as diagnosis tools (based on monitoring of equipment or process parameters), they provide different functionalities so they are here categorized separated. Prognosis approaches can be classified into three basic groups: model-based prognostics, datadriven prognostics, and experience-based prognostics [56]. An overview of prognosis technical approaches and the types of information needed for their implementation is given by [9].

- Cloud-based tools - These tools use cloud computing technology in order to provide the necessary resources to customers via information technology on-demand self-services over a network and independent of location and devices [57]. These applications are delivered as services over the Internet and can support different types of services: Software as a Service (SaaS), Infrastructure as a Service (IaaS) and Platform as a Service (PaaS) [39][58].

- Simulation tools - Simulation techniques have been largely used in maintenance for several purposes, such as to study different preventive maintenance and replacement strategies, to investigate the effect of different maintenance policies on production, to define the optimal maintenance workforce and inventory capacity [59]. An example of a simulation technique for maintenance is Monte Carlo simulation, which has been used for calculating the likelihood of failure occurrences [60] and for maintenance capacity planning [61]. Some authors propose simulation tools/applications which combine modelling and artificial intelligence techniques [62][63]. Moreover, [64] propose a simulation tool for the joint optimization of maintenance and spare parts inventory policies.

- Location and tracking tools - These tools may use wireless technology, such as RFID or GPS, due to their capability for assets tracking and handling, in order to provide location-based services [65]. Additional functionalities are to support operator and component identification, the storage of conventional data on the machine and also the traceability of the past maintenance actions [10].

- Augmented reality tools - These tools are built on innovative communication equipment (virtual reality) for supporting man/machine or man/man exchanges [10] and equipped with a see-through capability, which optically superimpose text and/or images computer, using half-silvered mirrors, onto directly real-world scenes [66]. They can use 3-D models and animations to show the information and the procedures to the operator [67]. There, these tools can provide support to operators for maintenance execution by showing the sequence of operations to perform [68] and by tracking the motion of operator's body, head, hands,.. [66]. 
Finally, the different categories for each technological level are summarized in Fig.3.

Fig. 3. Categories within the technological levels

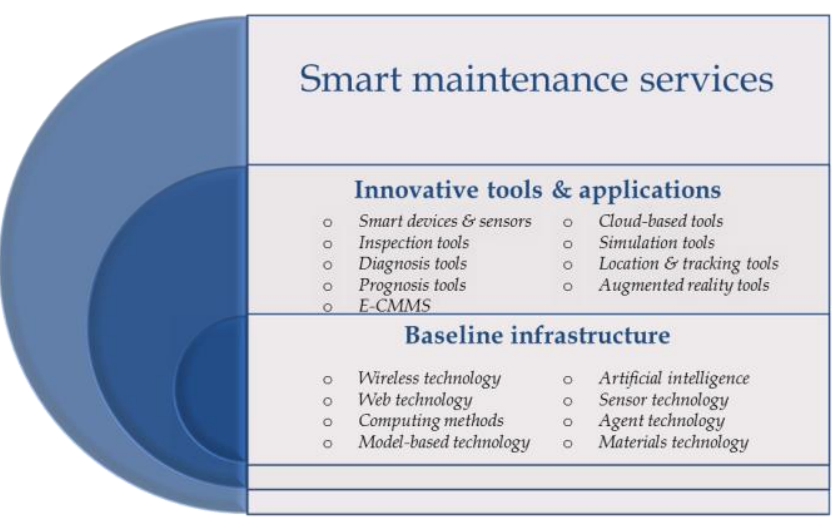

Although this proposal of technological levels is based on technology and maintenance related literature, some examples can be found in literature of technological tools which are used for the design or the delivery of smart maintenance services. For example, [69] propose a web-based intelligent fault diagnosis system for customer support, where the customer support is the smart maintenance service, the fault diagnosis system is a diagnosis tool within the intermediate level, and web technologies combined together with AI conform the elements at the baseline infrastructure level.

\section{VALUE CREATED BY INNOVATIVE TOOLS \& APPLICATIONS}

This section presents a review of new functionalities which can be provided by the different categories of innovative tools and applications defined above, as well as a depiction of the most used baseline technologies in some of the tool categories. Then, a proposal for a value analysis method and its potential applications is introduced. The method has been preliminary tested by the use of a survey distributed within experts on the fields of maintenance technologies and industrial services.

\section{A. Review of new functionalities and baseline technologies}

For each category of tools within the intermediate level of technological composition of smart maintenance services, the functionalities suggested in literature have been extracted and they are presented in Table 1 .

\section{TABLE I. NEW FUNCTIONALITIES FOR EACH CATEGORY}

\begin{tabular}{|c|l|l|}
\hline Category & \multicolumn{1}{|c|}{ Functionalities } & References \\
\hline $\begin{array}{c}\text { Smart } \\
\text { devices }\end{array}$ & $\begin{array}{l}\text { (1) support operator in the field; (2) take } \\
\text { remote action from anywhere }\end{array}$ & {$[10][40]$} \\
\hline $\begin{array}{c}\text { Smart } \\
\text { sensors }\end{array}$ & $\begin{array}{l}\text { (1) identify and report any malfunction of } \\
\text { system or equipmen; (2) perform data } \\
\text { manipulation and processing; (3) allow their } \\
\text { remote configuration and calibration }\end{array}$ & {$[41]$} \\
\hline e-CMMS & $\begin{array}{l}\text { (1) provide online information regarding } \\
\text { availability of workers and spare parts; (2) } \\
\text { allow fast and flexible scheduling; monitor and } \\
\text { manage preventive maintenance activities; (3) } \\
\text { connect with mobile technologies for retrieving }\end{array}$ & [10][[52] \\
\hline
\end{tabular}

\begin{tabular}{|c|c|c|}
\hline Category & Functionalities & References \\
\hline & data and loading maintenance action & \\
\hline $\begin{array}{l}\text { Inspection } \\
\text { tools }\end{array}$ & $\begin{array}{l}\text { (1) detect equipment or system failures; (2) } \\
\text { indicate equipment or system under- } \\
\text { performance; (3) deterioration and/or } \\
\text { functional degradation }\end{array}$ & {$[45][55]$} \\
\hline $\begin{array}{l}\text { Diagnosis } \\
\text { tools }\end{array}$ & $\begin{array}{l}\text { (1) on-line fault diagnosis; (2) fault and/or } \\
\text { degradation detection, isolation and root cause } \\
\text { identification }\end{array}$ & {$[34][40][49]$} \\
\hline $\begin{array}{l}\text { Prognosis } \\
\text { tools }\end{array}$ & $\begin{array}{l}\text { (1) failure prognosis based on current } \\
\text { condition and projected usage; (2) estimate the } \\
\text { remaining useful life (RUL) of system, } \\
\text { equipment or components; (3) analyse the } \\
\text { impact of component degradation on the } \\
\text { system to predict future system failures and } \\
\text { investigate possible maintenance actions; (4) } \\
\text { predict the future health of the system for each } \\
\text { potential degradation/failure mode }\end{array}$ & {$[34][40][70]$} \\
\hline $\begin{array}{c}\text { Cloud- } \\
\text { based tools }\end{array}$ & $\begin{array}{l}\text { (1) enable on-demand network access to a } \\
\text { shared pool of information resources; }(2) \\
\text { provide and release information resources with } \\
\text { minimal management effort or service provider } \\
\text { interaction }\end{array}$ & [39] \\
\hline $\begin{array}{l}\text { Simulation } \\
\text { tools }\end{array}$ & $\begin{array}{l}\text { (1) compare different maintenance policies; (2) } \\
\text { enable maintenance capacity planning; (3) } \\
\text { evaluate maintenance scheduling and } \\
\text { shutdown policy; (4) analyse different } \\
\text { scenarios for spare parts and material } \\
\text { management; (5) simulation of equipment } \\
\text { performance, deterioration and failure } \\
\text { occurencies }\end{array}$ & {$[45][59][61]$} \\
\hline $\begin{array}{l}\text { Location } \\
\text { and } \\
\text { tracking } \\
\text { tools }\end{array}$ & $\begin{array}{l}\text { (1) enable geolocalisation of maintenance } \\
\text { tools, operators, components and equiment; (2) } \\
\text { support operator, component and equipment } \\
\text { identification; (3) permit storage of } \\
\text { conventional data on the machine and } \\
\text { traceability of the past maintenance actions; (4) } \\
\text { transmit location, status and identification } \\
\text { information between components and } \\
\text { equipment }\end{array}$ & $\begin{array}{l}{[10][65][71]} \\
{[72]}\end{array}$ \\
\hline $\begin{array}{l}\text { Augmente } \\
\text { d reality } \\
\text { tools }\end{array}$ & $\begin{array}{l}\text { (1) support man/machine or man/man } \\
\text { exchange of information in the form of text } \\
\text { and fixed or animated images; (2) provide } \\
\text { guidance to operators for maintenance } \\
\text { intervention execution }\end{array}$ & {$[10][45]$} \\
\hline
\end{tabular}

Moreover, an analysis of the composition of different tools and applications has also been done in order to identify which are the most frequently used technologies within the baseline infrastructure level for each tool category. Fig. 4 shows the distribution of technologies composing the three most cited tool categories in literature which are: inspection, diagnosis and prognosis tools. The percentages refer to the number of articles which mentions that the technology is used to build up a tool included within the category, among all articles considering a tool of that category. It can be observed a high variety of baseline technologies for all categories. It is worth pointing out some differences between the three categories analyzed. Firstly, the three categories includes tools that are built on almost all baseline technologies, the only exception is agent technology, which is only used for diagnosis and prognosis tools. Inspection and diagnosis tools have similar distribution in technologies such as computing methods, wireless, web and model-based technologies and AI; however, authors in literature highlight more sensor and materials technologies for inspection tools rather than diagnosis tools. Diagnosis and 
prognosis tools have similar distributions regarding web and agent technology; the rest of technologies are more often cited in relation to prognosis (except for wireless and materials technologies). The greater differences are related to computing methods, AI, model-based and sensor technologies.

Fig. 4. Distribution of technologies within baseline infrastructure level

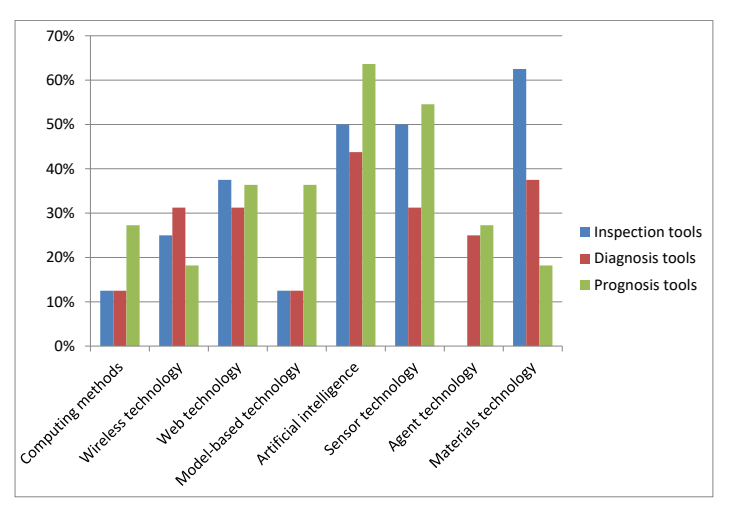

\section{B. Value analysis method}

As mentioned before, the value creation is a process which involves the creation of value for all actors participating in the provision of the service. The process of value creation has to be studied from a dual perspective: the value-in-use perspective, which refers to the voice of the customer, and the value-inoffering perspective, which represents the value proposed by the provider in their market offerings [16]. Concretely, considering the simplified case of one service provider and one customer, there are four possible scenarios depending on whether the value created for each of them is low or high during the provision of the service (see Fig. 5). High value perceived for the customer and high value in offering from the provider viewpoint are the elements of a win-win situation which is the most desired scenario, while unbalanced situations (representing high value-in-use and low value-in-offering or vice versa) could be allowed for a while but would not result on long-lasting customer-provider collaborations. The fourth scenario, in which both value-in-use and value-in-offering are low, is considered irrelevant. Implementing technology in the provision of maintenance services could contribute to achieve a balance between value from the customer and the provider perspectives. As an example, [73] point out that technology could increase the efficiency of internal operations of the service provider while keeping the same level of customer satisfaction. Thus, it could be seen as a means to pass from an unbalanced scenario where value-in-offering is low to a winwin scenario for both provider and customer.
Fig. 5. Different scenarios for service provision

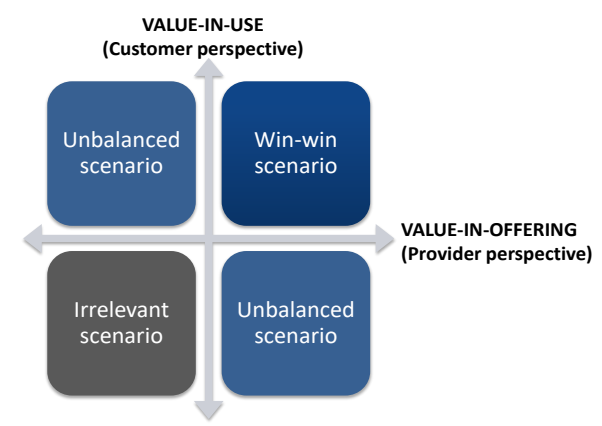

Several dimensions could be taken into consideration for analyzing the value created through the use of innovative tools and applications in service provision. In this work, the value dimensions are considered similar for customers and provider, although they would have different perspectives. The value dimensions selected to be analyzed for each tool category have been adapted from [27] and [74] and are defined as follows:

1) Service Reliability > This dimension concerns whether the service is performed how and when it was agreed.

2) Operator knowledge > This dimension is related to the know-how of the service operator for performing the work and solving emerging problems.

3) Safety at work > This dimension concerns whether the service provision is done according to safety policies and increased the operational safety of system/equipment.

4) Environmental safety > This dimension is related to the mitigation or elimination of environmental safety hazards during the provision of the service.

5) Service price > This dimension refers to the price of the service with respect to the received/provided service.

6) Technical quality > This dimension concerns the outcome of the service and whether is obtained as expected and during the agreed time

The method for value analysis is based on the evaluation of the different value dimensions according to a given scale of ordered, predefined scores, e.g. a Likert-type scale, which would provide the rating of each analyzed category or tool compared with the given rating scale. The suggested visual representation method for the results of this rating process is a radar chart. A radar chart has been previously suggested by [27] as a proper means to visualize the value gap between customer and provider valued elements. A radar chart representation is then adopted here to display the value of a tool category as it makes simpler to identify whether the category matches the value dimensions and in which degree. Moreover, it is possible to use this representation to analyze whether the value provided for each tool category covers the value dimensions targeted by the customer and/or provider, which themselves could also map their desired values in their own radar charts using the same value dimensions to this end.

This method has the potential to be used for the evaluation of broad categories of tools, as those defined in this paper, and for comparison between two or more tools within one category. Moreover, a complete technological solution for the provision of a service, encompassing several tools from different 
categories could be also assessed against customer and/or provider desired value dimensions by superposing the radar charts of the different tools, constructing in this way a global radar chart for the whole technological solution.

For the purpose of testing the adequacy of this analysis method, a first test has been done considering the defined tool categories. The data for this test have been obtained from a survey which has been carried out to analyze the potential contribution of each tool category with respect to each value dimension. More details are given in the next section.

\section{Preliminary survey results}

The data for testing the proposed value assessment and building preliminary radar charts for each tool category has been collected through a short survey sent to experts in the fields of maintenance technologies and maintenance service provision from both academy and industry. Till date some few experts have responded to the survey, so just the first preliminary results are explained in this section.

The survey has requested the respondents to rate in a 7 point Likert-type scale the contribution of each tool category to each value dimension. The scale used is shown in Fig 6. The use of this scale allows to identify whether the contribution of the tool category to a value dimension is considered to have a positive effect, a negative effect or neither of them. Overall scores for each tool category have been also calculated as well as the detached scores for each value dimension. The first observable result of the responses obtained is that the service price is often affected negatively by tool categories with higher positive scores in the other value dimensions. The overall score has been then calculated without considering the score given to service price, which is studied separately in the remaining from the rest of value dimensions. Fig. 7 shows the overall scores for each tool category without considering the score of their effect on service price. It can be observed that four categories have an overall score below five

Fig. 6. Likert-type scale used in data collection

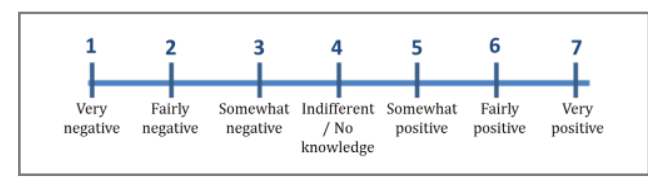

Fig. 7. Overall score for each tool category

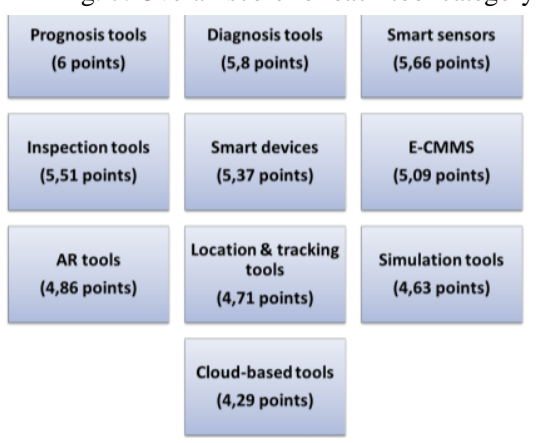

A first analysis of responses have been done by evaluating the frequency of the score 4 given to each tool category, which could indicate either that the tool category does not have an effect on the value dimension (neither negative nor positive) or that the effect is unknown. Two tool categories have received high number of score 4 in several value dimensions (cloudbased tools and simulation tools) and less overall score, therefore, their potential use for service provision is not clear with respect to the value dimensions.

A specific analysis of responses regarding the effects on service price indicates that two groups can be identified. The first group, compound by six categories - smart devices, inspection tools, diagnosis tools, prognosis tools, e-CMMS and simulation tools - would have a high negative effect on service price. The second group includes four group categories - smart sensors, cloud-based tools, location and tracking tools and AR tools - which have a moderate negative effect on service price.

The analysis of responses regarding the positive effects of the tool categories with respect to the value dimensions enables the radar chart representation of each category. Two possible uses of the value analysis method can be reflected based on the data collected from the survey. The first use is the display of scores obtained in each value dimension for each tool category independently. Fig 8 shows the results of four tool categories. It is worth noting that smart devices, although not getting very high scores, are those providing more balanced contribution to all value dimensions. Smart sensors and inspection tools, however, are seen as those categories contributing more to service reliability. Operator knowledge obtained moderate positive effects, in general, for almost all tool categories, which could be explained as these tools may be seen more as a support to maintenance activities and decision making rather than a source of increased knowledge for the operator.

Fig. 8. Value analysis of four tool categories

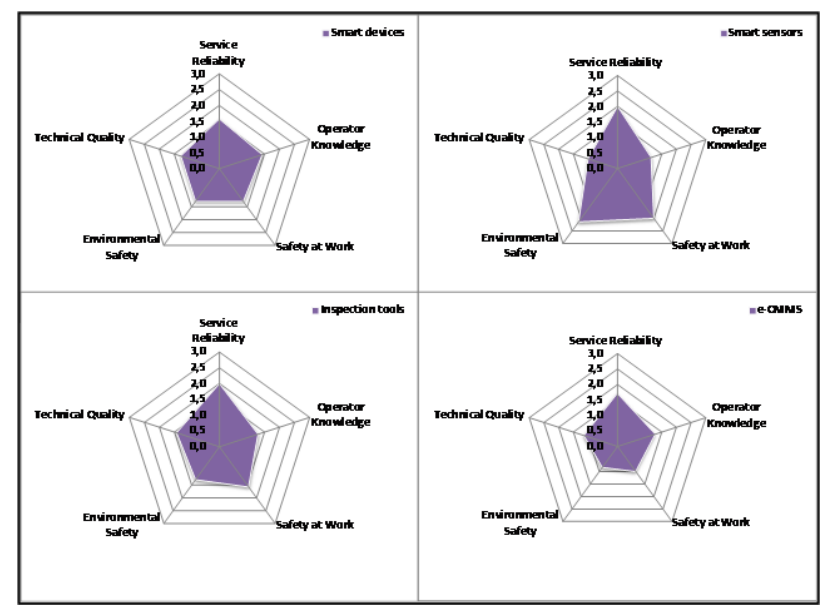

The second use concerns the comparison between two tool categories in the same radar chart. Fig. 9 shows the radar chart comparing the two tool categories which received higher overall scores: prognosis tools and diagnosis tools. Prognosis tools obtain slightly higher scores in most value dimensions, except for operator knowledge dimension. It is interesting to note that service reliability is perceived to be highly impacted by prognosis tools; indeed, they obtained the highest score among all tool categories in this value dimension. 
Fig. 9. Comparison between the value analysis of two categories

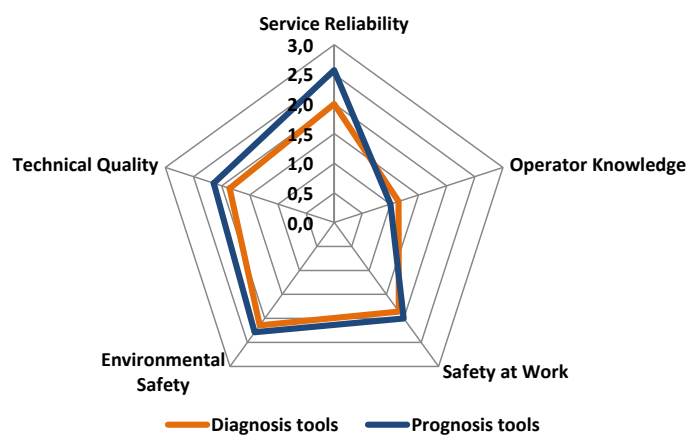

This second use of the value analysis method could be also employed for evaluating several tools within a tool category and for assessing the achievement of targeted value-in-use or value-in-offering of a technological solution, which would be potentially built up on a combination of different tools pertaining to one or more categories. This can be done by superposing the scores desired in each value dimension for customer's value-in-use and/or provider's value-in-offering together with the scores given by the technological solution.

\section{CONCLUDING REMARKS}

This work contributes to the understanding of the role and contribution that E-maintenance technologies play to support servitization strategies and to increase the value created by maintenance services. An illustration of two envisaged technological levels that constitute an offering of smart maintenance services and a proposal of categorization within each technological level have been presented here. This permits to make an initial analysis of the potential contribution of different tool categories to several value dimensions in maintenance services. A radar chart representation has been selected as the preferred visualization method for value analysis due to its wide possibilities for displaying several dimensions at the same time. Two potential uses of this value analysis method has been illustrated here. Further work would extend the uses of the value analysis to explore whether concrete desired value-in-use, from customer perspective, or value-in-offering, from provider perspective, are achieved through a technology-based solution which encompasses one or more innovative tools / applications.

Additionally, a more in-depth study is needed in order to attain a more operational level in the value analysis of maintenance services. The work presented here and the previous studies regarding the assessment of value elements or dimensions in maintenance service provision do not focus on the operational values of the service performed, e.g. equipment reliability or availability are not considered as value elements although they may be desired outcomes of service provision. A suggested analysis at operational level would need to take into account the specific operating conditions of target equipment, such as its criticality for plant operations and the failure consequences on environmental and human safety.

\section{REFERENCES}

[1] J. Sachs, The end of proverty: economic possibilities for our time, New York: Penguin Books, 2005
[2] G. Dosi, "Technological paradigms and technological trajectories. A suggested interpretation of the determinants and directions of technical change,” Research Policy, vol. 11, pp. 147-162, 1982

[3] W.J. Abernathy and K.B. Clark, "Innovation: mapping the winds of creative destruction," Research policy, vol. 14, pp.3-22, 1985

[4] R. Garcia and R. Calantone, "A critical look at technological innovation typology and innovativeness terminology: a literature review," The Journal of Product Innovation Management, vol. 19, pp. 110-132, 2002

[5] J. Lee and E. Lapira, "Predictive Factories: The Next Transformation," Manufacturing Leadership Journal, Frost Sullivan, Feb. 2013 Issue.

[6] J. Lee, "A framework for Web-enabled e-maintenance systems," Environmentally Conscious Design and Inverse Manufacturing, In:Proceedings EcoDesign 2001,pp. 450-459, 2001

[7] J. Davis, T. Edgar, J. Porter, J. Bernaden and M. Sarli, "Smart manufacturing, manufacturing intelligence and demand-dynamic performance," Computers and Chemical Engineering, vol. 47, pp. 145156,2012

[8] M. Koç, J. Ni, J. Lee and P. Bandyopadhyay, "Introduction to emanufacturing." In: The Industrial information technology handbook. Ed: Zurawski, R. Industrial Electronics Series, 2005

[9] A. Muller, A. Crespo Marquez and B. Iung, "On the concept of emaintenance: Review and current research," Reliability Engineering and System Safety, vol. 93, pp. 1165-1187, 2008

[10] B. Iung, E. Levrat, A. Crespo Marquez and H. Erbe, "Conceptual framework for e-Maintenance: Illustration by e-Maintenance technologies and platforms," Annual Reviews in Control, vol. 33, pp. 220-229, 2009

[11] E. Levrat, B. Iung and A. Crespo Marquez," E-maintenance: review and conceptual framework," Production Planning and Control, vol.19 (4), pp. 408-429, 2008

[12] T. Laine, J. Paranko, M. Varila and P. Suomala, "Diffusion os industrial services: is it another story?," In: proceedings of the IEEE engineering management society conference, vol. 1, pp. 363-368, 2005

[13] T.S. Baines, H.W. Lightfoot, O. Benedettini, J.M. Kay, "The servitization of manufacturing: A review of literature and reflection on future challenges," Journal of Manufacturing Technology Management, vol. 20(5), pp. 547-567, 2009

[14] P. Johansson and J. Olhager, "Industrial service profiling: matching service offerings and processes," Int. J. Production Economics, vol. 89, pp. 309-320, 2004

[15] L.S. Vargo and R.F. Lusch, "Evolving to a new dominant logic for marketing," Journal of marketing, vol. 68, pp. 1-17, 2004

[16] L. V. Ngo and A. O'Cass, “ Creating value offerings via operant resource-based capabilities," Industrial marketing management, vol. 38, pp. 45-59, 2009

[17] V. Ojanen, T. Ahonen and M. Reunanen, "Availability and sustainability as value elements in assessing customer value of an industrial service," Technology Management in the Energy Smart World (PICMET), 2011 Proceedings of PICMET '11, pp.1-11, 2011

[18] R. Oliva and R. Kallenberg, "Managing the transition from products to services," International Journal of Service Industry Management, vol. 14(2), pp. 160-172, 2003

[19] N. Morelli, "Developing new product service systems (PSS): methodologies and operational tools," Journal of Cleaner Production, vol., 14, pp.1495-1501, 2006

[20] A. Neely, O. Benedettini and I. Visnjic, "The servitization of manufacturing: further evidence," 18th European Operations Management Association Conference, Cambridge, July 2011

[21] S. Brax, "A manufacturer becoming service provider - challenges and a paradox," Managing Service Quality, vol. 15 (2), pp. 142-155, 2005

[22] D. Miller, Q. Hope, R. Eisenstat, N. Foote and J. Galbraith,"The problem of solutions: balancing clients and capabilities," Business Horizons, vol. 45 (2), pp. 3-12, 2002

[23] U. Kumar, “ System Maintenance: Trends in Management and Technology," in Handbook of Performability Engineering, K. B. Misra, Ed. Springer London, pp. 773-787, 2008 
[24] T. Grubic, "Servitization and remote monitoring technology. A literature review and research agenda," Journal of Manufacturing Technology Management, vol. 25, pp. 100-124, 2014

[25] S. Barile and F. Polese, "Smart service systems and viable service systems: applying systems theory to service science," Service Science, vol. $2(1 / 2)$, pp. $21-40,2010$

[26] P. Carbonell, A.I. Rodriguez-Escudero and D. Pujari, "Customer involvement in new service development: an examination of antecedents and outcomes," J. Prod. Innov. Manag. Vol, 26, pp. 536-550, 2009

[27] M. Ali-Marttila, L.Tynninen, S.Marttonen and T. Kärri, "Solving the value puzzle of the customer and service provider in industrial maintenance services," Proceedings of the Maintenance Performance Measurement and Management Conference, S. Monto, M. Pirttilä, T. Kärri (editors), pp. 234-248, 2013

[28] A. Toosi, H.L. Lockett, J.Z. Raja and V. Martinez, "Assessing the value dimensions of outsourced maintenance services," Journal of Quality in Maintenance Engineering, vol. 19(4), pp. 348-363, 2013

[29] G. Allmendinger and R. Lombreglia, "Four strategies for the age of smart services," Harvard Business Review, October 2005

[30] J. Lee and M. AbuAli, "Intelligent Maintenance Systems Next 5 Years and Beyond: Transforming Condition-based Maintenance to Productivity and Service Innovation," Keynote Paper, 22th International COMADEM Conference, 2009

[31] R. Kumar, T. Markeset and U. Kumar, "Maintenance of machinery negotiating service contracts in business-to-business marketing, " International Journal of Service Industry Management, vol. 15 (4), pp. 400-413, 2004

[32] J. Campos, "Development in the application of ICT in condition monitoring and maintenance," Computers in Industry, vol. 60, pp. 1-20, 2009

[33] T. Han and B-S. Yang, "Development of an e-maintenance system integrating advanced techniques," Computers in Industry, vol. 57, pp. 569-580, 2006

[34] A.K.S. Jardine, D. Lin and D. Banjevic, "A review on machinery diagnostics and prognostics implementing condition-based maintenance," Mechanical Systems and Signal Processing, vol. 20, pp. 1483-1510, 2006

[35] M. Wooldridge, N.R. Jennings, "Intelligent agents: Theory and practice," The Knowledge Engineering Review, vol. 10 (2), pp. 115-152, 1995

[36] J. Lee, M. Ghaffari and S. Elmeligly, "Self-maintenance and enginering inmune systems: towards smarter machines and manufacturing systems," Annual Reviews in Control, vol. 35, pp. 111-122, 2011

[37] S. Zhang, X. Chen, S. Zhang, and X. Huo, "The comparison between cloud computing and grid computing," in Computer Application and System Modeling (ICCASM), 2010 International Conference on, vol. 11,2010 , pp. $72-75$

[38] I. Foster, Y. Zhao, I.Raicu and S.Lu, "Cloud computing and grid computing 360-degree compared," Grid Computing Environments Workshop, 2008. GCE '08, pp. 1-10

[39] T. Dillon, C. Wu and E. Chang, "Cloud computing: issues and challenges," 2010 24th IEEE International Conference on Advanced Information Networking and Applications, pp. 27-33, 2010

[40] A. Crespo Marquez and B. Iung, "A Review of e-Maintenance Capabilities and Challenges," Journal of Systemics, Cybernetics and Informatics, vol. 6, pp. 62-66, 2008

[41] Y. Zhang, Y. Gu, V. Vlatkovic and X. Wang, "Progress of smart sensor and smart sensor networks," IEEE Publications, pp. 3600-3606, June 2004

[42] S. Kurada and C. Bradley, "A review of machine vision sensors for too condition monitoring," Computers in industry, vol. 34, pp. 55-72, 1997

[43] B. Tao, H. Ding and Y.L. Xiong," "IP sensor and its distributed networking application in e-maintenance," Systems, Man and Cybernetics. IEEE International Conference on, vol. 4, pp.3858-3863, October 2003

[44] J. Lee, J. Ni, D. Djurdjanovic, H. Qiu and H.Liao, "Intelligent prognostics tools and e-maintenance," Computers in Industry, vol. 57, pp. 476-489, 2006
[45] S. Takata, F. Kimura, F.J.A.M van Houten, E. Westkämper, M. Shpitalni, D. Ceglarek, J. Lee, "Maintenance: changing role in life cycle management,"Annals of the CIRP, vol. 53 (2), pp. 643-656, 2004

[46] A.Y.C Nee, S.K. Ong, G. Chryssolouris and D. Mourtzis, "Augmented reality applications in design and manufacturing," CIRP Annals in Manufacturing Technology, vol. 61, pp. 657-679, 2012

[47] J. D. Achenbach, "Quantitative non-destructive evaluation," International Journal of Solids and Structures, vol. 37, pp. 13-27, 2000

[48] K.T. Gillen, M. Celina and R.L. Clough, "Density measurements as a condition monitoring approach for following the aging of nuclear power plant cable materials," Radiation Physics and Chemistry, vol. 56, pp. 429-447, 1999

[49] A.H.C. Tsang, “ Condition-based maintenance:tools and decision making," Journal of Quality in Maintenance Engineering, vol. 1(3), pp. 3-17, 1995

[50] M.C. Carnero, "Selection of diagnostic techniques and instrumentation in a predictive maintenance program. A case study," Decision Support Systems, vol. 38, pp. 539- 555, 2005

[51] N.D.R. Goddard, R.M.J. Kemp and R. Lane, "An overview of smart technology," Packaging technology and science, vol. 10, pp. 129-143, 1997

[52] L. Pintelon, N. Du Preez and F. Van Puyvelde, "Information technology: opportunities for maintenance management," Journal of Quality in Maintenance Engineering, vol. 5, pp. 9-24, 1999

[53] J.F. Gomez Fernandez and A. Crespo Marquez, "Maintenance Management in Network Utilities. Framework and Practical Implementation," Springer Series in Reliability Engineering. SpringerVerlag London, 2012

[54] O. Duran, "Computer-aided maintenance management systems selection based on a fuzzy AHP approach," Advances in Engineering Software, 42, 821-829, 2011

[55] R. Kumar, S.S. Panesar and T. Markeset, "Development of technical integrity management services - a concept," Journal of Quality in Maintenance Engineering, vol. 15(3), pp. 271-284, 2009

[56] R. Gouriveau and K. Medjaher, "Industrial prognosis - An overview," In: Maintenance Modelling and Applications, (Eds.), John Andrews, Christophe Berenguer, Lisa Jackson, 2011, pp. 10-30, Det Norske Veritas, Høvik

[57] S. Marston, Z. Li, S. Bandyopadhyay, J. Zhang and A. Ghalsasi, "Cloud computing - the business perspective," Decision Support Systems, vol. 51, pp. 176-189, 2011

[58] M. Armbrust et al., " A view of cloud computing," Communications of the ACM, vol. 53 (4), pp. 50-58, 2010

[59] A. Andijani and S. Duffuaa, "Critical evaluation of simulation studies in maintenance systems," Production Planning \& Control: The Management of Operations, vol. 13(4), pp. 336-341, 2002

[60] M. Tsutsui and S. Takata, "Life cycle maintenance planning method in consideration of operation and maintenance integration," Production Planning \& Control: The Management of Operations, vol. 23(2-3), pp. 183-193

[61] A. Crespo Marquez, The maintenance management framework: models and methods for complex systems maintenance, Springer Series in Reliability Engineering, Springer-Verlag London, 2007

[62] M. Marseguerra, E. Zio and L. Podofillini, "Condition-based maintenance optimization by means of genetic algorithms and Monte Carlo simulation," Reliability Engineering and System Safety, vol. 77, pp. 151-166, 2002

[63] A. Oyarbide-Zubillaga, A. Goti and A. Sanchez, "Preventive maintenance optimisation of multiequipment manufacturing systems by combining discrete event simulation and multi-objective evolutionary algorithms," Production Planning \& Control: The Management of Operations, vol. 19(4), pp. 342-355, 2008

[64] R. Saker and A. Haque, "Optimization of maintenance and spare provisioning policy using simulation," Applied Mathematical Modelling, vol. 24, pp. 751-760, 2000

[65] C. Emmanouilidis, J.P. Liyanage and E. Jantunen, "Mobile solutions for engineering asset and maintenance management," Journal of Quality in Maintenance Engineering, vol. 15 (1), pp. 92-105, 2009 
[66] S. Zlatanova, Augmented Reality Technology, GIS Report No.17, Delft, December 2002

[67] I. Porcelli. M. Rapaccini, D.B Espíndola, C.E. Pereira, "Innovating product-service systems through augmented reality: a selection model," In: The Philosopher's Stone for Sustainability, Y. Shimomura and K. Kimita (Eds), Springer Berlin Heidelberg, pp. 137-142, 2013

[68] F. De Crescenzio, M Fantini, F. Persiani, L. Di Stefano, P. Azzari and S. Salti, "Augmented Reality for Aircraft Maintenance Training and Operations Support," IEEE Computer Graphics and Applications, vol. 31, no. 1, pp. 96-101, Jan.-Feb. 2011

[69] S. C. Hui, A.C.M. Fong and G. Jha, "A web-basedintelligent fault diagnosis system for customer service support," Engineering applications of artificial intelligence, vol. 14, pp. 537-548, 2001

[70] A. Voisin, E. Levrat, P. Cocheteux and B. Iung, "Generic prognosis model for proactive maintenance decision support: application to pre- industrial e-maintenance test bed,” J. Intell. Manuf., vol.21, pp. 177-193, 2010

[71] H. Ramamurthy, B.S. Prabhu and R. Gadh, "Smart sensor platform for industrial monitoring and control," In Proceedings of the 4th IEEE conference on sensors, pp. 1116-1119, 2005

[72] A. Adgar, D. Addison, C-Y. Yau, "Applications of RFID technology in maintenance systems," In: Proceedings of the second World Congress on Engineering Asset Management (WCEAM),, June 2007

[73] S. Agnihothri, N. Sivasubramaniam, D. Simmons, "Leveraging technology to improve field service," International Journal of Service Industry Management, vol. 13(1), pp. 47-68, 2002

[74] T. Sinkkonen, H. Kivimaki, S. Marttonen and T. Karri, "A value-based life-cycle framework for networks of industrial maintenance services," In: Proceedings of COMADEN 2013, pp. 1-13, 2013 